\title{
Characterization of Cure of Carbon/Epoxy Prepreg Used in Aerospace Field
}

\author{
Michelle Leali Costa ${ }^{\mathrm{a} *}$, Edson Cocchieri Botelho ${ }^{\mathrm{a}, \mathrm{b} *}$, Jane Maria Faulstich de Paiva ${ }^{\mathrm{a}, \mathrm{c} *}$, \\ Mirabel Cerqueira Rezende ${ }^{\mathrm{a} *}$ \\ ${ }^{a}$ Materials Division, AMR, Instituto de Aeronáutica e Espaço, Centro Técnico Aeroespacial, \\ Praça Marechal do Ar Eduardo Gomes, $n^{\circ}$ 50, Vila das Acácias, \\ 12228-904 São José dos Campos - SP, Brazil \\ ${ }^{\mathrm{b}}$ Fatigue and Aeronautic Material Research Group, Department of Material and Technology, \\ UNESP, Guaratinguetá - SP, Brazil \\ ${ }^{\circ}$ Centro Universitário Salesiano de São Paulo - UNISAL, Campus Dom Bosco, \\ Unidade de Americana - SP, Brazil
}

Received: November 25, 2004; Revised: May 2, 2005

\begin{abstract}
Carbon/epoxy 8552 prepreg is a thermoplastic toughened high-performance epoxy being used in the manufacture of advanced army material. Understanding the cure behavior of a thermosetting system is essential in the development and optimization of composite fabrication processes. The cure kinetics and rheological behavior were evaluated using a differential scanning calorimetry (DSC), dynamic mechanical analysis (DMA) and a rheometer. Values of the kinetic parameters were obtained from dynamic DSC scans using an nth order reaction model. Rheological measurements as a function of temperature and time were made for the prepreg system. The manufacturer's recommended cure cycle was evaluated and considered adequate to consolidated the studied system.
\end{abstract}

Keywords: carbon/epoxy prepreg, kinetic of cure, DSC, rheology, DMA

\section{Introduction}

Preimpregnated fibers or prepregs have been widely used to produce high quality composite parts. Interest in the kinetics and mechanisms of epoxy resin curing used in prepregs derives from its use in reinforced composites. Chemical reactions that take place during the cure determine the resin morphology, which, in turn, determines the properties of the cured thermoset resin. Processingmorphology-property relationships of various epoxy resin formulations have been investigated. The first essential step in this evaluation process is to understand the mechanism and the kinetic involved in the curing reactions ${ }^{1-7}$.

Excellent reviews concerning mechanisms and kinetics of thermoset cure are presented in literature ${ }^{1,8-11}$. Despite the considerable current research effort in the field of epoxy resin cure, numerous issues have yet to be addressed. There is a number of partially conflicting explanations proposed in recent years for the reaction mechanisms of epoxy system cure ${ }^{1-9}$.

There has been an increased interest in modeling of epoxy-based composite processing with the growth of computer-aided design and manufacturing ${ }^{1}$. The aim is to optimize the processing parameters to obtain high quality parts with greater consistency and to minimize the experimental work required to establish a cure cycle for new components. A good model enables one to predict how the system will behave during cure and what will be the final condition. One of the most important tools of such models is a description of the kinetics of cure. With the chemistry of epoxy curing being rather complex and not completely understood, the cure kinetics is not easily elucidated ${ }^{1,7,12}$.

A variety of experimental techniques has been used to monitor the cure reaction of thermosetting systems, among them, the differential scanning calorimetry (DSC), dynamic mechanical analysis (DMA) and rheological analysis can be cited. DSC can measure the heat flow required to maintain a sample at a given temperature, providing information on cure and degradation reactions. In the DMA test, the specimen is loaded in bending and force and displacement measurements are used to characterize the material.

The rheological characterization of composite matrix resins is of ever-increasing importance in recent years ${ }^{13,14}$. Information about flow, gel temperature and minimum viscosity is used to select new resin systems and to establish preliminary processing parameters ${ }^{13,14}$. Substantial efforts have been devoted to develop proper methodologies for characterizing the cure cycle in prepreg systems as well as to investigate the behavior of different systems. However, few studies have been reported in the open literature. Therefore, the rheological evaluation of carbon fiber/epoxy prepregs deserves further attention. In rheological analyses, the molecular mobility is measured as a function of temperature or time. Changes in molecular mobility are indicative of viscosity changes during the cure. The combined results of DSC and DMA techniques provide an in-depth characterization of the material thermal properties ${ }^{13,14}$.

The most important problem related to the use of epoxy resins in preimpregnated systems is that they are inherently brittle materials ${ }^{9}$. This has been the subject of many studies involving the toughening of the epoxy matrices without compromising their desirable attributes, such as their high glass transition temperature $\left(\mathrm{T}_{\mathrm{g}}\right)$, high modulus and advantageous strength to weight ratios. Thermoplastic and rubber additives have received much attention to reach this goal due to their ductile nature, high $\mathrm{T}_{\mathrm{g}}$ and high modulus. They have proved to be very effective for highly crosslinked epoxy resin systems ${ }^{4}$. As a result of the intimate relationship between network structure, mechanical properties and reaction kinetics, it is important to understand 
the reaction kinetics of the epoxy cure. However, the introduction of thermoplastic or rubber modifiers can cause further complexities resulting from the interactions between the thermoplastic/or rubber and epoxy materials, which may affect the cure process ${ }^{4}$.

In this work, DSC, DMA and rheological techniques were used to investigate some of the kinetic parameters of cure reactions of a recent 8552-epoxy system modified with thermoplastic, impregnated into carbon reinforcement, and to evaluate the curing cycle used to manufacture polymeric composites for aeronautical applications. The basic assumption used is that the heat evolution recorded by DSC is proportional to the extent of consumption of epoxy group in the epoxy resin or the reactive group in the curing agent. Kinetic data are obtained from dynamic DSC and rheological measurements and both dynamic and isothermal DMA measurements during the curing reactions.

\section{Experimental Procedure}

\subsection{Materials}

Carbon fabric reinforced 8552-epoxy (prepreg), supplied by Hexcel Composites, was studied in this work. The epoxy matrix is amine and thermoplastic toughened and the carbon fabric is manufactured with T300 fiber.

\subsection{Prepreg analysis}

Differential scanning calorimetry (DSC) can measure the heat that is either absorbed or evolved during the course of a chemical reaction. Since epoxy reactions release energy during the cure (i.e. they are exothermic) DSC is a conventional tool for monitoring their cure. The used equipment was a DSC Pyris from Perkin Elmer. The raw data was automatically sent to a computer and evaluated using software called Pyris Kinetics.

The uncured prepreg samples (8552-epoxy), weighing about $5 \mathrm{mg}$, were placed in an aluminum pan with a sealed lid and placed opposite to the empty reference pan in the oven chamber. The DSC was then set for temperature range of 30 to $300{ }^{\circ} \mathrm{C}$ with three different heating rates: $2.5 ; 5.0$ and $10.0^{\circ} \mathrm{C} . \mathrm{min}^{-1}$.

Rheological data were obtained using a Rheometric Scientific, model SR-5, with parallel plates and controlled stress rheometer. Three heating rates were investigated: $2.5 ; 5.0$ and $10.0^{\circ} \mathrm{C} . \mathrm{min}^{-1}$, with a constant frequency of $1 \mathrm{rad} . \mathrm{s}^{-1}$ and stress $1000 \mathrm{~Pa}$, to identify changes in the viscosity profiles and gel temperatures of prepreg system.

For the dynamic mechanical analyses the prepreg samples were cut in the dimensions of $40 \mathrm{~mm} \times 13 \mathrm{~mm}$ (length and width). A thermal analyzer (DMA) TA2980 of TA Instruments operating in the single cantilever horizontal measuring system was used to evaluate the specimens. The DMA equipment was calibrated using a metallic standard. The used experimental conditions were: oscillation amplitude $(20 \mu \mathrm{m}), 1 \mathrm{~Hz}$ frequency, heating rate $\left(2.5^{\circ} \mathrm{C} \cdot \mathrm{min}^{-1}\right)$ and temperature range of $30-300{ }^{\circ} \mathrm{C}$. Before starting every experiment, the equipment was stabilized at $30^{\circ} \mathrm{C}$ by 3 minutes.

\section{Results}

\subsection{Differential scanning calorimetry}

Figure 1 shows a typical dynamic DSC curve obtained for the 8552-epoxy system. The area above the peak at the exothermic region was used to determine the fractional conversion of the epoxy resin; by assuming that the heat evolved during cure is directly related to the disappearance of the epoxy groups during the reaction.
The parameters kinetics in this work were obtained by dynamic DSC scans using an $n$th order reaction models, according to Equation $1^{3-12,18}$.

$$
\frac{d \alpha}{d t}=k(1-\alpha)^{n}
$$

where: $\alpha$ is the degree of chemical conversion, $n$ is the order of the reaction, $k$ is the reaction rate constant and $d \alpha / d t$ is the derivative $\alpha$ with respect to time or temperature or reaction rate.

Table 1 shows all kinetic parameters obtained by dynamic method for the three heating rates: $2.5 ; 5.0$ e $10.0{ }^{\circ} \mathrm{C} . \mathrm{min}^{-1}$ of carbon/8552-epoxy resin prepreg. $T_{\text {initial }}$ and $T_{\text {final }}$ describe the temperature rate in that the prepreg cure kinetic was studied, always keeping the onset in 5\% and offset in $90 \%$ of conversion, once that is known that in the beginning of reaction the process is very fast and disordered, therefore it is difficult to establish any kinetic parameter in this phase. In a similar way, in the final of reaction, few groups are still available to react and again the description of cure in this phase is not representative of the kinetic as a whole ${ }^{8}$.

It is verified that the onset of an exothermic event is registered at lower temperatures for slower heating rates because the lower heating rate favors a larger number of chemical groups to react. In the same way, the enthalpy and the order of reaction increase with the decrease of the heating rate. The enthalpy and the order of reaction are related to the area above the DSC curve, which is directly proportional to the epoxy groups consumed during the cure 4 .

The reaction heat values, $\Delta H$, vary over the range 578-596 J.g $\mathrm{g}^{-1}$ with a mean value of $494{\mathrm{~J} . g^{-1}}^{-}$for the carbon/8552-epoxy prepreg. The order of reaction found for the carbon/8552-epoxy prepreg is in the range of 1.3-0.9 with the average $n=1.1$. These data suggest a strong dependence among the kinetic parameters and the reaction heat with the heating rate.

The activation energy, $E_{a}$, was determined using the variation of the maximum temperature of the exothermic peak with the heating rate based on the Ozawa and Arrhenius method ${ }^{11,12}$. The calculated mean value of Ea for the prepreg system is: $58.5 \pm 1.6{\mathrm{~kJ} . \mathrm{mol}^{-1}}^{-}$for the 8552-epoxy.

The values obtained for the pre-exponential constant $\left(\sim 9.9-8.7 \mathrm{~s}^{-1}\right)$ and the activated energy are in agreement with the literature data for reac-

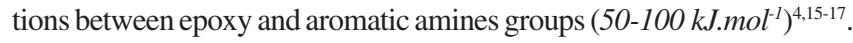
It is also necessary to do a simulation involving the composite processing into the autoclave by using the prepreg.

The DSC curve obtained by heating rate of $2.5^{\circ} \mathrm{C} \cdot \mathrm{min}^{-1}$ was chosen to represent the prepreg system (Figure 1). This heating rate

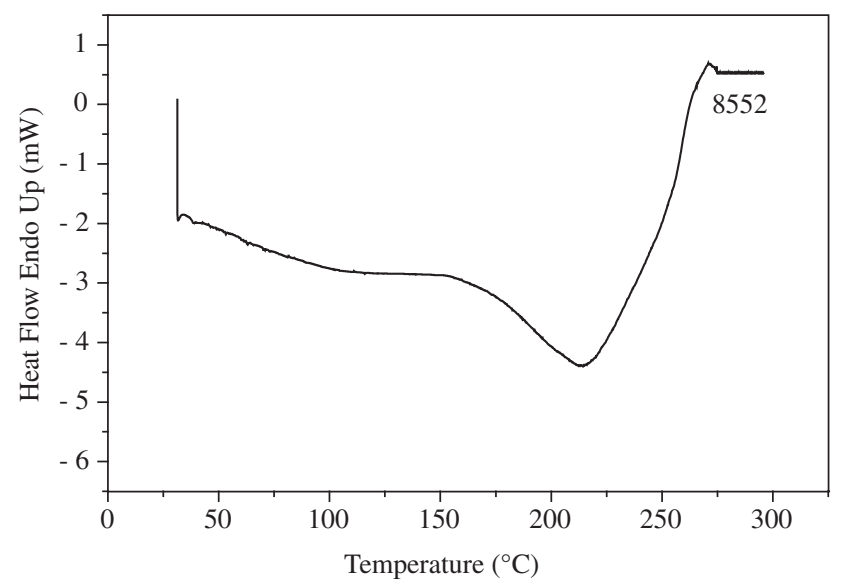

Figure 1. Typical dynamic DSC curve of the 8552 prepreg at the heating rate of $2.5^{\circ} \mathrm{C} \cdot \mathrm{min}^{-1}$. 
was used as reference because it is the rate employed industrially in the autoclave to cure the prepreg studied in this work.

Four steps constitute the cure cycle suggested by the prepreg supplier. Firstly, the temperature is raised from 30 to 116 at $2.5^{\circ} \mathrm{C} . \mathrm{min}^{-1}$; holding at $116^{\circ} \mathrm{C}$ for 60 minutes (second step); following the temperature is raised until $177{ }^{\circ} \mathrm{C}$ using the same heating rate (third step); holding at this temperature for at least 120 minutes (fourth step). Based on this information, a mathematical simulation of the degree of conversion of the 8552-epoxy resin was carried out and represented in Figures 2a-2d.
Figure $2 \mathrm{a}$ presents the simulation of the prepreg system conversion degree as function of temperature for a time interval of 34.4 minutes; this is the time necessary to elevate the temperature from 30 to $116^{\circ} \mathrm{C}$, using the heating rate of $2.5^{\circ} \mathrm{C} \cdot \mathrm{min}^{-1}$. This curve was obtained based on Equation 2, using a predetermined time and temperature range:

$$
\alpha=1-\left[1-(1-n) \cdot A \cdot t \cdot \exp \left(-E_{a} / R T\right)\right]^{(1 /(1-n))}
$$

Figure 2a shows the conversion degree of the carbon/8552-epoxy prepreg as function of temperature as a simulation of the curing

Table 1. Kinetic parameters obtained by dynamic DSC method for carbon/8552-epoxy resin prepreg.

\begin{tabular}{cccccccc}
\hline $\begin{array}{c}\text { Matrix of } \\
\text { Prepreg }\end{array}$ & $\begin{array}{c}\text { Heating rate } \\
\left({ }^{\circ} \mathrm{C} . \mathrm{min}^{-1}\right)\end{array}$ & $T_{\text {initial }}\left({ }^{\circ} \mathrm{C}\right)$ & $T_{\text {final }}\left({ }^{\circ} \mathrm{C}\right)$ & $-\Delta H\left(J . g^{-1}\right)$ & $\ln A\left(\mathrm{~s}^{-1}\right)$ & $E_{a}\left(\mathrm{~kJ} . \mathrm{mol}^{-1}\right)$ & $n$ \\
\hline 8552 & 2.5 & 140 & 237 & 587 & $7.3 \pm 0.9$ & $54.6 \pm 2.2$ & $1.3 \pm 0.1$ \\
& 5.0 & 144 & 237 & 578 & $9.9 \pm 0.4$ & $62.4 \pm 1.8$ & $1.2 \pm 0.1$ \\
& 10.0 & 151 & 246 & 596 & $8.9 \pm 0.2$ & $58.4 \pm 0.8$ & $0.9 \pm 0.1$ \\
\hline
\end{tabular}

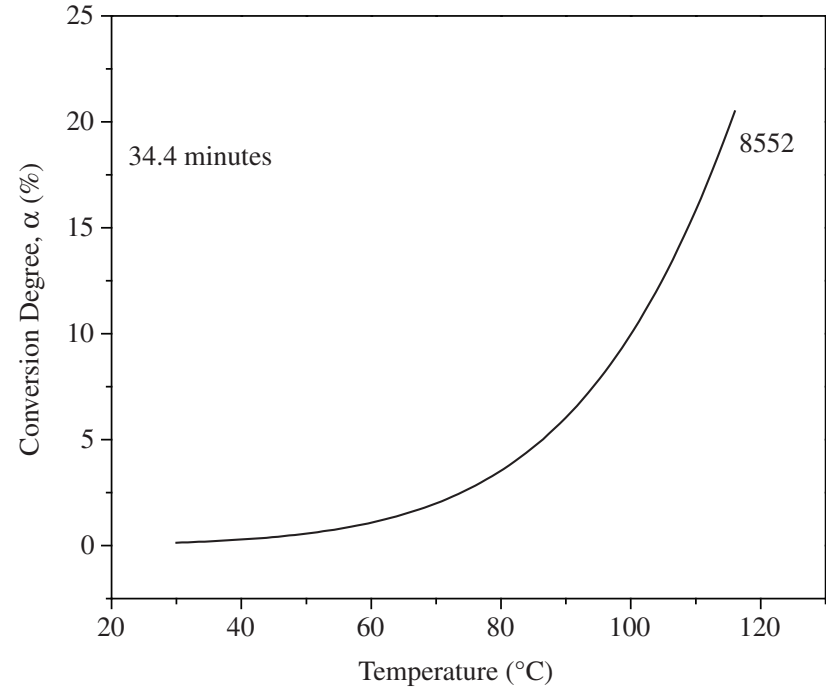

(a)

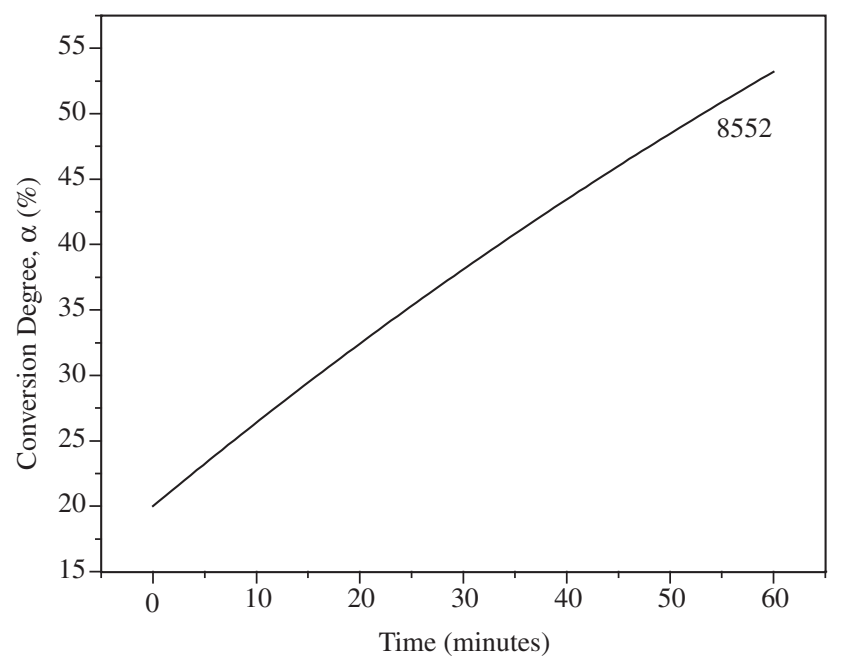

(b)

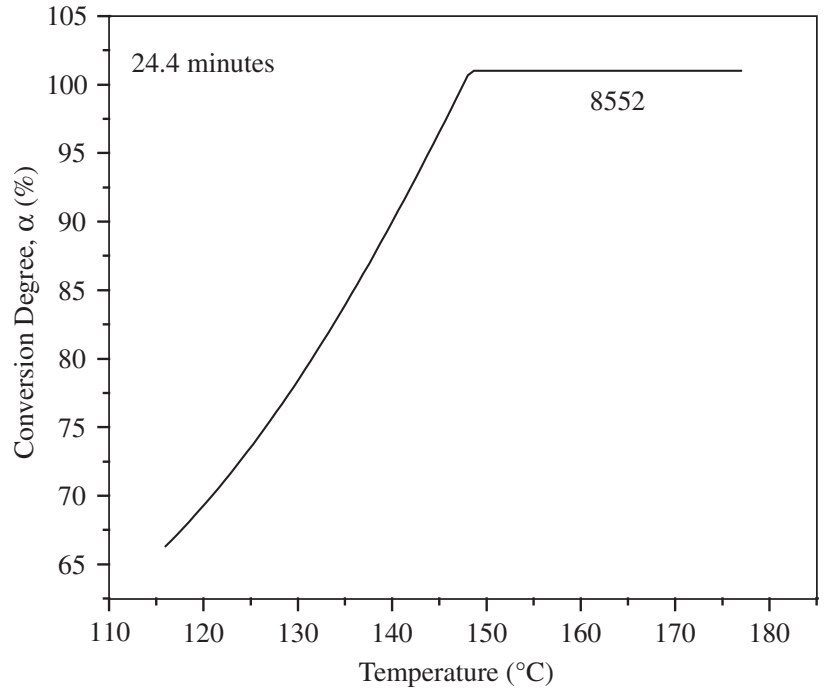

(c)

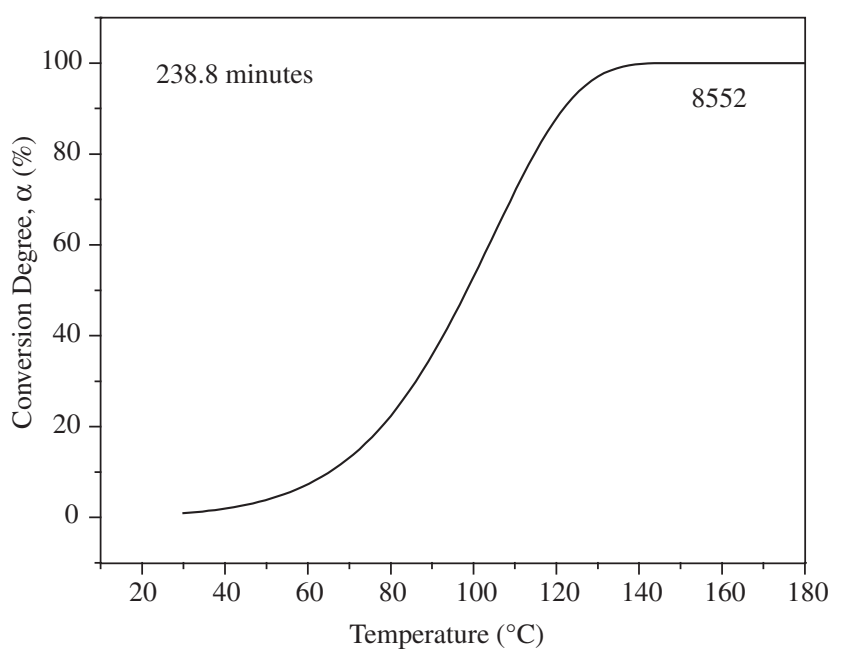

(d)

Figure 2. a) Degree of conversion, $\alpha$, for the carbon/8552-epoxy prepreg as function of temperature $\left(30-116{ }^{\circ} \mathrm{C}\right)$; b) as function of time (isothermal: $116{ }^{\circ} \mathrm{C}$ ); c) as function of temperature $\left(116-177^{\circ} \mathrm{C}\right)$; and d) as function of total temperature (complete cure cycle). 
process carried out in the autoclave. It can be observed a conversion degree of $20 \%$, corresponding to the reactions between epoxy and primary amine groups, resulting in secondary and tertiary amines, besides the production of hydroxyl groups that catalyze the polymerization reaction ${ }^{11,12,17}$.

Figure $2 b$ shows the conversion degree simulation related to the second step in the autoclave, where the samples are kept under isothermal condition as function of time, according to Equation 2. It can be observed that the cure process reaches $53 \%$ of conversion. At this phase, there is the presence of some molecules that are reaching the gelation process and others that already passed over by process. Thus, the cure process goes on more slowly due to the reduced mobility of the molecules, caused by the increase of crosslink density.

Figure $2 \mathrm{c}$ shows the simulation of the third step of the curing process of the carbon/8552-epoxy prepreg in the autoclave. This curve shows almost $100 \%$ of conversion degree for the epoxy resin that occurs in the temperature range of 116 to $177^{\circ} \mathrm{C}$ during 24.4 minutes.

Finally, the fourth step is necessary to guarantee that all structure reaches the complete cure, independently of the thickness, and the polymeric composite reaches the best performance in terms of their mechanical properties, the curing cycle is kept at least 120 minutes at $177^{\circ} \mathrm{C}$. Figure $2 \mathrm{~d}$ depicted all cure cycle used to obtain the carbon fiber/8552 epoxy composites. It can be observed that in the final of cycle the material found completely cured.

\subsection{Dynamic mechanical analysis}

Dynamic mechanical analysis was done to complete the investigation of the curing of 8552-epoxy resin prepreg. Figure 3 shows the DMA of the prepreg samples submitted at the same heating rate as suggested by the prepreg supplier and previously described in this work. According to the DMA curve (Figure 3), upon initial heating the stiffness of the prepreg decreased drastically due to the epoxy resin viscosity decrease. As the material is continuously heated, it begins its cure ${ }^{3}$.

With the temperature increase, during the scanning, a significant increase of the material storage modulus $\left(E^{\prime}\right)$ occurs indicating that the curing process promotes the increase of the stiffness of the samples, attributed to the crosslinking density increase of the 8552-epoxy resin.

It is important to observe that the moduli measurements present noise, mainly the loss modulus ( $E$ ”). Probably, this noise is related to the small spaces among the carbon fibers of the fabric reinforcement

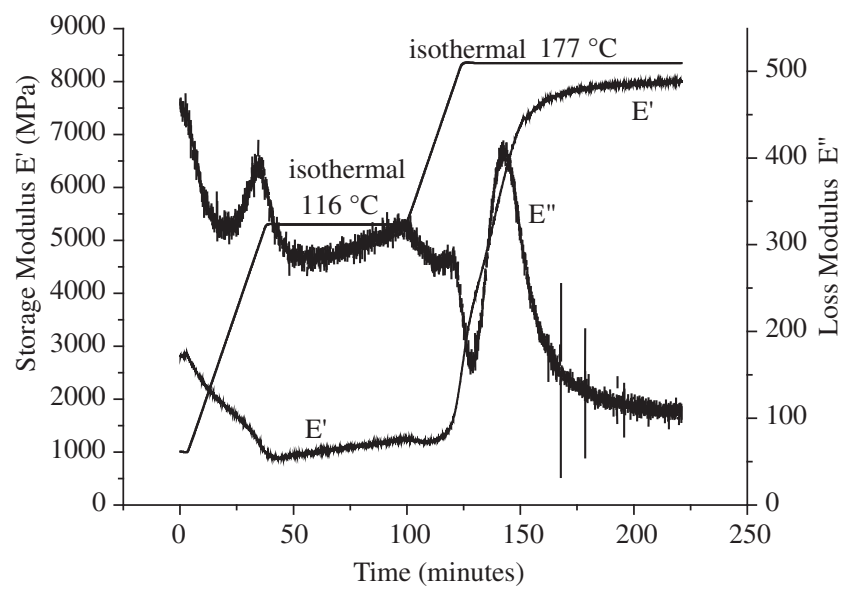

Figure 3. DMA curves of curing of carbon fabric/8552-epoxy prepreg. Heating rate of $2.5^{\circ} \mathrm{C} \cdot \mathrm{min}^{-1}$ and also to the resin migration towards these small voids during the curing process. Besides that, the noise appeared in the DMA curves due to the uncured prepreg ply, used to simulate the cure was not compacted or molded.

Comparing the DMA curves of Figure 3 with Figure 2a, which shows that after the isothermal at $116{ }^{\circ} \mathrm{C}$ the percentage of cure of the prepreg is about $34 \%$, it can be observed that this curing percentage does not cause significant increase in the material stiffness (determined by storage modulus $E^{\prime}$ ). However, it is necessary to emphasize that the isothermal at $116{ }^{\circ} \mathrm{C}$ is important in the material curing process, because this step favors increase of the epoxy matrix crosslinking density, aided by application of pressure and vacuum during the prepreg consolidation in the autoclave. In this step, defects as voids can occur caused by volatile release during the curing process.

After the isothermal at $116^{\circ} \mathrm{C}$ it is observed a gradual increase of the storage modulus $E^{\prime}$ until the second isothermal at $177^{\circ} \mathrm{C}$. In this step it occurs a large number of crosslinking reactions in the resin increasing the storage modulus $E$ ' to a maximum value. The obtained results show that using one single layer of prepreg it is possible to simulate the curing process. In this work the values of $E$ ' are used only to monitor the cure process and this value does not correspond to the $E$ ' obtained by conventional mechanical tests, for example, tensile tests. It is important to mention that the $E$ ' value obtained by DMA is not in agreement with the elasticity modulus for this carbon fabric composite due to the anisotropy of the analyzed sample and to the analysis characteristic of the DMA equipment. Discrepancies are introduced because of the high stiffness and orthotropic nature of the tested specimens. Therefore, the values of elastic modulus $E$ ' should be regarded as qualitative results for comparison purposes. On the other hand, the DMA technique is one of the most adequate tools to be used in order to measure the glass transition phenomenon and the modulus value can be used in order to compare and to support discussions involving processing parameters and interface studies ${ }^{3,16,18-20}$.

The increase of the storage modulus reaching a maximum during the crosslinking was also reported in literature $e^{3,5,16,18}$. These data are in accordance with Figure $2 \mathrm{~d}$, which shows that the isothermal at $177^{\circ} \mathrm{C}$ increased the crosslinking density of the 8552-epoxy matrix until nearly $100 \%$.

Figure 3 shows also that during the isothermal at $177^{\circ} \mathrm{C}$ the prepreg presents a peak $\left(\sim 150^{\circ} \mathrm{C}\right)$ attributed to the loss modulus $E$ ". This peak is related to the glass transition region of the prepreg resin and it is attributed to vibrations and movements of some parts of the polymeric chains.

Figure 4 shows the DMA curve $\left(30-300{ }^{\circ} \mathrm{C}\right)$ of the prepreg previously cured by using the same curing cycle used in the analyses. Comparing Figure 4 with Figure 2 obtained by DSC, it can be observed that the epoxy matrix was properly cured.

Figure 4 shows that the cure steps carried out for the 8552-epoxy resin prepreg were enough to promote the resin cure, since the respective storage modulus $E$ ' did not present any increase during the analysis ${ }^{3,5}$. This Figure shows also that the cured prepreg presents a small decrease in storage modulus $E$ ' until to $190^{\circ} \mathrm{C}$, practically not changing its mechanical property. A significant decreasing of storage modulus $E$ ' occurs from $190^{\circ} \mathrm{C}$. The loss modulus $E$ " and tan delta (loss factor) also increase characterizing the glass transition region (225-250 $\left.{ }^{\circ} \mathrm{C}\right)$. So, the application of this material need to attend temperature values lower than $190^{\circ} \mathrm{C}$. Also because starting from $190{ }^{\circ} \mathrm{C}$ occur loss modulus and tan delta changes.

\subsection{Rheological analysis}

The correlation between viscoelastic parameters and temperature or viscoelastic parameters and time of thermoset resins or prepreg systems has shown effectiveness for support the composite manufacture. 


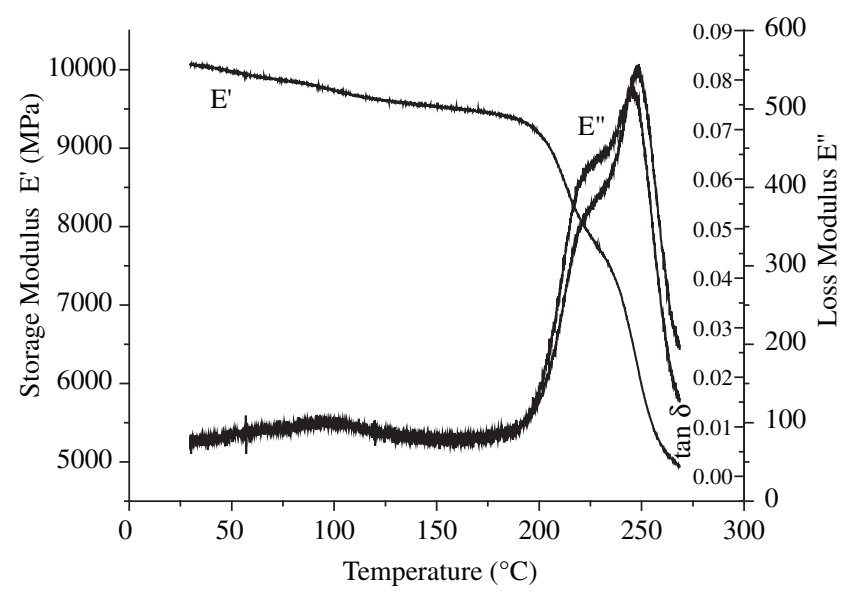

Figure 4. DMA curves of cured carbon fabric /8552-epoxy resin prepreg. Heating rate of $2.5^{\circ} \mathrm{C} \cdot \mathrm{min}^{-1}$.

The viscosity control during the consolidation process of composite materials allows the optimization of the resin infiltration inside the reinforcement favoring, consequently, a larger densification of the composite materials in a shorter time.

Figure 5 and Table 2 present the rheological parameters for carbon fabric/8552-epoxy resin prepreg analyzed at 2.5, 5 and $10{ }^{\circ} \mathrm{C} \cdot \mathrm{min}^{-1}$. As can be observed, firstly the increase of the temperature causes a decrease of the viscosity until a minimum point. From this point, the polymerization reaction takes place and an increase of the complex viscosity is observed due to the formation of a three-dimensional net of crosslinked molecules.

The decrease of the complex viscosity, observed in the first part of the curve (Figure 5) is attributed to a gradual destruction of the existent interaction forces (van der Waals forces). This viscosity behavior, particularly for the system studied in this article, indicates that the increase of heating rate induces an increase of the minimum temperature value.

The composite processing control requires the knowledge of the rheological behavior of the impregnant system during the polymerization reaction. The gel temperature of the resin is characteristic of each system, being dependent on its chemical nature, purity, useful life and the cure degree of the thermoset resin. In the gel temperature region a three-dimensional infinite net coexists with numerous free chains. After the system to reach the gel temperature region, the net of polymeric chains increases. As a consequence of the polymerization reaction, the molecular chains of the polymer grow, later they ramify and as a function of the crosslinking density, their flexibility and mobility decrease.

The gel temperature can be obtained from a tangent to the evolution of the complex viscosity curve (Figure 5), characterized by no increase of the crosslinking density of the polymer. Despite the evolution of the complex viscosity to supply referring data to the gel region, it is more appropriate to use the crossing of $G^{\prime}$ with $G$ " (Figure 5). In the same way that the complex viscosity analyses, it is observed that the gel temperature values, obtained by crossing $G$ ' and $G$ ", show that the gel temperature values increase with the increase of heating rate (comparing with the heating rate to $2.5^{\circ} \mathrm{C} \cdot \mathrm{min}^{-1}$, the gel temperature increase in $9 \%$ and $19 \%$ for heating rate of 5 and $10{ }^{\circ} \mathrm{C} / \mathrm{min}$, respectively), therefore, the gel temperature obtained by complex viscosity was lower than that ones obtained by crossing loss and storage moduli (decrease in $12 \%, 7 \%$ and $14 \%$ for the heating rate of $2.5,5$ and $10{ }^{\circ} \mathrm{C} \cdot \mathrm{min}^{-1}$, respectively). From this, it can be concluded that different heating rates during the cure of 8552 resin

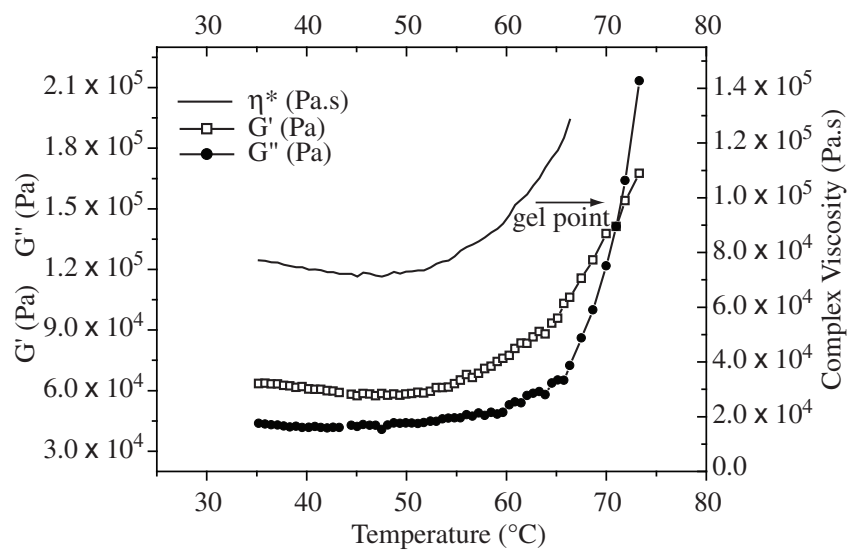

(a)

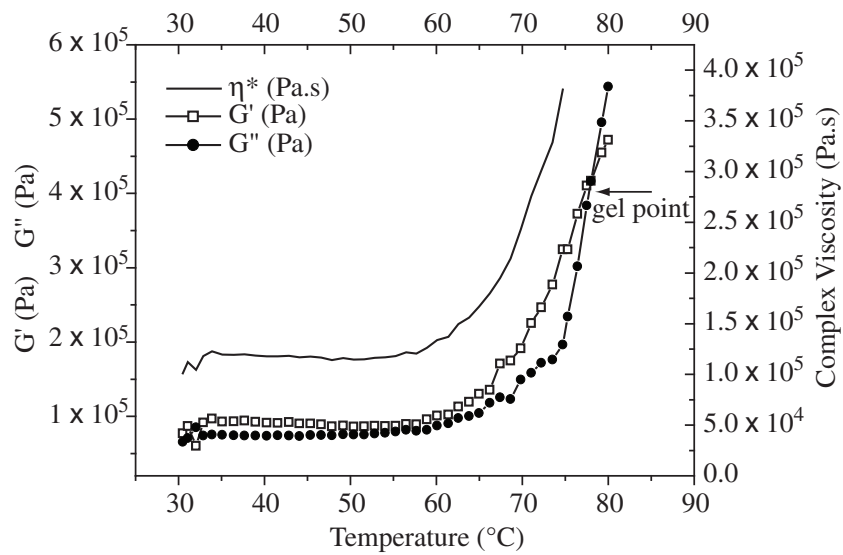

(b)

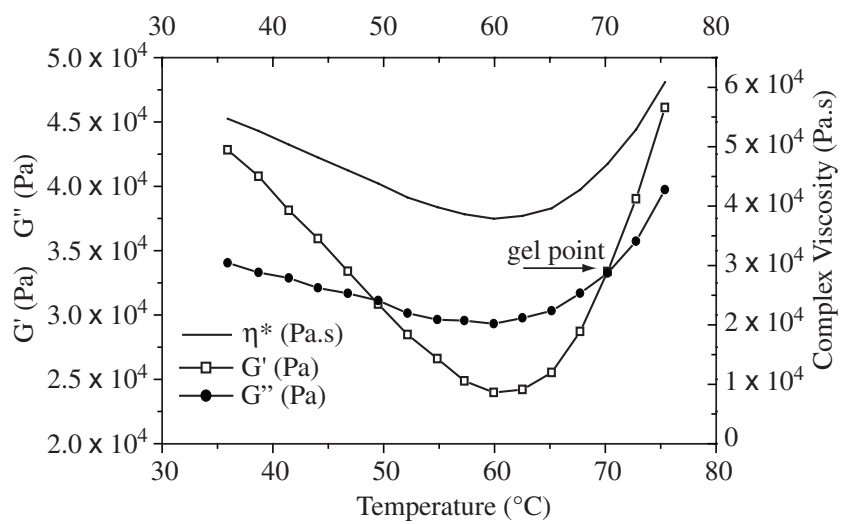

(c)

Figure 5. Rheograms of carbon fiber/8552-epoxy resin prepreg system: a) $2.5^{\circ} \mathrm{C} \cdot \mathrm{min}^{-1}$; b) $5{ }^{\circ} \mathrm{C} \cdot \mathrm{min}^{-1}$; and c) $10^{\circ} \mathrm{C} \cdot \mathrm{min}^{-1}$.

Table 2. Rheological parameters of 8552-epoxy prepreg.

\begin{tabular}{cccccc}
\hline $\begin{array}{c}\text { Heating rate } \\
\left({ }^{\circ} \mathrm{C} . \mathrm{min}^{-1}\right)\end{array}$ & \multicolumn{3}{c}{$\begin{array}{c}\text { Complex viscosity } \\
\text { parameters }\end{array}$} & \multicolumn{2}{c}{$\begin{array}{c}\text { Modulus } \\
\text { parameters }\end{array}$} \\
& $\begin{array}{c}\eta_{\text {minimum }} \\
(\mathrm{MPa})\end{array}$ & $\begin{array}{c}T_{\eta \text { minimum }}\left({ }^{\circ} \mathrm{C}\right) \\
\left.{ }^{\prime} \text { ( }\right)\end{array}$ & $\begin{array}{c}T_{\text {gel }} \\
\left({ }^{\circ} \mathrm{C}\right)\end{array}$ & $\begin{array}{c}G^{\prime}=G^{\prime} \\
(\mathrm{MPa})\end{array}$ & $\begin{array}{c}T_{g e l} \\
\left({ }^{\circ} \mathrm{C}\right)\end{array}$ \\
\hline 2.5 & 24 & 55 & 63 & 141 & 71 \\
5.0 & 15 & 58 & 73 & 413 & 78 \\
10.0 & 38 & 63 & 75 & 180 & 87 \\
\hline
\end{tabular}


present different polymerization reaction kinetic and lower heating rate during the autoclave processing results in slow polymerization rate. Consequently, this result favors a more appropriate cure cycle for the composite manufacture, decreasing the probability of defects and porosity and increasing, consequently, the mechanical properties.

Considering that the autoclave processing involves several steps, such as reinforcement and resin choice, vacuum/pressure cycles, the curing cycle must consider the gel temperature, heating rate and the initial and final temperatures of polymerization. This way allows that the carbon fiber/epoxy composite processing can be executed with safety and reliability. Correlating DSC, DMA and rheological data it is possible to establish a more appropriate curing cycle for carbon fiber /8552-epoxy system in order to produce a composite material with quality to be used as aircraft structural component. This study benefits directly the aerospace area allowing establishing adequate curing cycle aiming the composite material manufacture.

\section{Conclusion}

It was observed that the carbon fiber/8552-epoxy prepreg shows kinetic of cure with $n$ reaction order and the heating rate more adequate to manufacture the polymeric composite is $2.5^{\circ} \mathrm{C} \cdot \mathrm{min}^{-1}$. This heating rate provides a cure more homogeneous and controlled than 5 and $10{ }^{\circ} \mathrm{C} \cdot \mathrm{min}^{-1}$. These results were confirmed by rheological analyses, which show that lower heating rate promotes lower gel temperature values and, this way, not so fast cure kinetic during the 8552-epoxy polymerization.

The use of DSC, DMA and rheological analyses showed adequate to establish appropriate curing cycle for carbon fiber/8552-epoxy resin system in order to produce composite material with quality to be used in structural components. This study benefits directly the aerospace area where an inadequate cure cycle can be detrimental for the composite material processing.

\section{Acknowledgments}

The authors acknowledge the financial support received, respectively, from FAPESP under grants 02/01808-7; 02/01288-3 and $02 / 02057-5$ and CNPq under grant 300599/96. The authors are indebted to Hexcel for supplying the test material and dpUNION to loan the DMA equipment model 2980 from TA Instruments.

\section{References}

1. Ghaemy M, Riahy MH. Kinetics of anhydride and polyamide curing of bisphenol A-based diglycidyl ether using DSC. European Polymer Journal. 1996; 32(10):1207-1212.

2. Buggy M, Temimhan T, Braddell O. Curing of carbon fibre reinforced epoxy matrix composites. Journal of Materials Processing Technology. Jan 1996; 56(1-4):292-301.

3. Shim SB, Seferis JC, Eom YS, Shim YT. Thermal characterization and comparison of structural prepregs with different cure temperatures. Thermochimica Acta. 1997; 291(1-2):73-79.
4. Varley RJ, Hodgkin JH, Hawthorne DG, Simon GP, McCulloch D. Toughening of a trifunctional epoxy system Part III. Kinetic and morphological study of the thermoplastic modified cure process. Polymer. Apr 2000; 41(9):3425-3436.

5. Hayes BS, Gilbert EN, Seferis JC. Scaling complications of dual temperature cure resin prepreg systems in airplane part manufacture. Composites Part A Applied Science and Manufacturing. 2000; 31(7):717-725.

6. Zvetkov VL. Comparative DSC kinetics of the reaction of DGEBA with aromatic diamines. II. Isothermal kinetic study of the reaction of DGEBA with m-phenylene diamine. Polymer. Febr 2001; 42(4):6687-6697.

7. Costa ML, Botelho, EC, Rezende MC. Monitoring of cure kinectic prepreg and curing cicle modeling. Journal of Materials Processing Technology. 2005; in press.

8. Prime RB. In: EA Tori. Thermal characterization of polymeric materials. ed. New York: Academic Press; 1981, p. 435.

9. May, CA. Epoxy resins chemistry and technology. ed. Watsonville, USA: Marcel Dekker, 1998.

10. Costa ML, Rezende MC, Pardini LC. Estudo da influência do diluente reativo PGE na cinética de cura de resina epóxi utilziada em compósitos estruturais. Química Nova. mai-jun 2000; 23(3):320-325.

11. Costa ML, Pardini LC, Rezende MC. Métodos de Estudo da Cinética de Cura de Resinas Epóxi. Polímeros: Ciência e Tecnologia. abr-jun 1999; 2:37-44.

12. Paiva, JMF, Costa ML, Rezende MC. Evaluation of thermal stability and glass transition temperature of different aeronautical polymeric composites. Polymer Plastic Technology and Enginering. 2005; in press.

13. Botelho E C, Scherbakoff N, Rezende M C. Rheological Studies Applied in the Processing and Characterization of Carbon/Carbon Composites. Journal of Advanced Materials. 2001; 33(4):44-51.

14. Botelho EC, Scherbakoff N, Rezende MC. Rheological Analysis of the Phenolic and Furfuryl Resins Used in the Carbon Materials Processing. Materials Research. 2000; 3(2):19-23.

15. Barral L, Cano J, López JI, López-Bueno PN, Torres A, Ramirez C, Abad MJ. Decomposition behavior of epoxy-resin systems cured by diamines. Thermochimica Acta. Jun 2000; 36(6):1231-1240.

16. Wingard CD. Characterization of prepreg and cured epoxy/fiberglass composite material for use in advanced composite piping systems. Thermochimica Acta. 2000; 357-358:293-301.

17. Shin DD, Hahn HT. A consistent cure kinetic model for AS4/3502 graphite/epoxy . Composites Part A Applied Science and Manufacturing. Sept 2000; 31(9):991-999.

18. Costa ML, Paiva JMF, Botelho EC, Rezende MC. Avaliação Térmica e Reológica do Ciclo de Cura do Pré-mpregnado de Carbono/Epóxi. Polímeros: Ciência e Tecnologia. jul-set 2003; 13(3):188-197.

19. Tanoglu M, Robert S, Heider D, McKnigth SH, Brachos V, Gillespie Jr. JW. Effects of thermoplastic preforming binder on the properties of S2-glass fabric reinforced epoxy composites. International Journal of Adhesion \& Adhesives. 2001; 21:187-195.

20. Keusch S, Haessler R. Influence of surface treatment of glass fibres on the dynamic mechanical properties of epoxy resin composites . Composites Part A Applied Science and Manufacturing. Aug 1999; 30(8):997-1002. 